\title{
Formation and Analysis of Labor Cost Variance Based on Standard Cost Method of Cost Management
}

\author{
Zhiying Liu, Jinlong Wang \\ Harbin Finance University 150030
}

Keywords: labor variance analysis system; standard cost method; indirect cost; labor cost

\begin{abstract}
Standard cost method plays an important role in the system of product cost accounting, as a result the research on it includes the aspects of material cost, labor cost and indirect cost. However, there are more studies on material cost and indirect cost, and less on variance analysis of labor cost. With the popularization of machine manufacturing and the application of artificial intelligence, the labor cost has a new change with a downward trend, but it cannot be replaced in the short term and will still weigh in the manpower-intensive production enterprises. In this paper, firstly focuses were laid on the manpower-intensive production enterprises and non-customized production enterprises, and then efforts were made to further refine and decompose the labor variance on the basis of traditional labor variance analysis, and finally a more reasonable and practical analysis system was established, so as to provide data support for the standard cost variance analysis later.
\end{abstract}

\section{Background}

Product cost consists of three major factors: material, labor and indirect expenses including wages. The importance of wages varies with the nature of enterprises. According to the difference of labor proportion, enterprises can be divided into labor-intensive and capital-intensive. At present, labor-intensive industries mainly refer to agriculture, forestry, textile, clothing, toys, leather, furniture and other manufacturing industries where the proportion of labor cost is relatively high. Due to the imbalance of industrial development in China, a considerable part of labor is still unable to be technicalized. Even if it can, in the case of capital shortage and relatively low labor cost, the cost of using technology is often higher than that of using labor ${ }^{1]}$. Without doubt with the progress of technology and the application of new process equipment, as well as the adjustment of national industrial policy layout, the technology and capital intensity of labor-intensive industries are also increasing, and gradually differentiated from them. Moreover, it is possible that artificial intelligence in computer technology can replace manual labor in a large area, and the proportion of human cost will be greatly reduced in the future. In capital-intensive enterprises, although the proportion of machinery and equipment is large, a certain proportion of labor costs will also be involved. It is thus clear that labor cost is still worthy of research at present, but the research and control of it in labor-intensive enterprises is more valuable.

The product cost is basically composed of three parts: direct material, direct labor and manufacturing cost. As the expense in the second place, the input of labor cost will affect the product cost, so it has been a key point of enterprise cost control, and also a national concern in recent years.

The macro management of labor cost in China includes the following stages. In the first stage, from 1978 to 1990, the wage distribution of state-owned enterprises focused on implementing the principle of distribution according to work and encouraging enterprises to strive to improve economic efficiency. Cost accounting was involved in the Accounting Law, Accounting Standards for Business Enterprises and Financial System for Industrial Enterprises, but there was no specific provision for labor cost treatment. In the second stage, from 1991 to 1996, with the rapid development of reform and opening up, how to manage the labor cost had become an urgent problem to be solved. The most concerned department was the Ministry of Labor, proposing to designate a cost management method. In this stage, the focus of work was to control the labor cost 
and strengthen the control of the total amount of labor wages through the labor cost management system. In the third stage, from 1997 to 2003, on the basis of the pilot project in the previous stage, in-depth investigation was carried out to start macro management of labor cost. In the fourth stage, from 2004 to 2012, the system was gradually formed, and the macro management framework of labor cost had been basically established. In the fifth stage, from 2012 to now, the macro management system of labor cost has been further enriched and improved. In 2018, the promulgation of the State Council's [2018] No. 16 document Opinions of the State Council on Reforming the Wage Decision Mechanism of State-owned Enterprises marked a new step in the macro management of labor costs. The guiding ideology of the Opinions is to establish and improve the wage decision and normal growth mechanism that are basically adapted to the labor market and linked to the economic benefits and labor productivity of state-owned enterprises, improve their wage distribution supervision system, fully mobilize the enthusiasm, initiative and creativity of their employees, further stimulate their creativity and improve market competitiveness, promote the state-owned capital to be stronger, better and bigger, and promote the income distribution to be more reasonable and orderly ${ }^{[2]}$. In August 2019, the Ministry of Water Resources issued the Measures for the Implementation of the Reform of Wage Decision Mechanism of Enterprises Affiliated to the Ministry of Water Resources and supporting measures (hereinafter referred to as the Implementation Measures), proposing to establish and improve the wage decision and normal growth mechanism that are basically adapted to the labor market and linked to the economic benefits and labor productivity of state-owned enterprises centering on enhancing the vitality and efficiency of state-owned enterprises, adhere to the classified management at different levels, and improve the wage distribution supervision system of state-owned enterprises ${ }^{[3]}$. The right of wage distribution within enterprises shall be implemented in accordance with the law, so as to promote more reasonable and orderly distribution of enterprises, further stimulate the creativity of state-owned enterprises and improve their market competitiveness. It is thus clear that labor cost management has entered the deepening stage.

\section{Actual Labor and Standard Labor}

At the enterprise level, there are two systems of labor cost accounting, namely the actual labor system and the standard labor system. Labor cost of an enterprise refers to the sum of all direct and indirect expenses incurred by an enterprise in the production, operation and provision of labor services in a certain period of time. Under the actual labor system, the labor cost of product cost is included in the product cost according to the actual labor cost. Under the standard labor system, the labor cost of product cost is included in the product cost according to the standard labor.

\subsection{Understanding of actual labor}

Under the actual cost system, first of all, the actual labor occurred should be collected, and then distributed on this basis in combination with feasible and reasonable methods. There are two understandings of labor cost in broad and narrow senses. In a broad sense, labor cost should be allocated and included in the corresponding cost according to different departments and purposes. In a narrow sense, labor cost only involves cost of goods manufactured. Enterprises focus on product cost control, so the labor cost of this part is in a narrow sense. Under the actual cost method, labor cost collection goes through two steps. First, specify the organization and personnel of labor cost management. Labor cost management in an enterprise is a systematic project, which requires the enterprise to carry out in a systematic, all-round, and whole process way, which can only be carried out after going through the necessary approval procedures and being approved, so as to reduce labor cost; and tom supervise and check the accuracy of reports of subordinate units and departments, release the labor cost status of the whole enterprise, and provide other labor cost information consultation required by each unit. Secondly, establish the labor cost statistical account. The influencing factors of actual cost include working hours and wage rate, which may change with the increase of labor productivity and social average rate of return, which shall be learnt and understood by the personnel of labor management. 


\subsection{Understanding of standard labor under standard cost method}

Target cost is the estimate of cost, which refers to the pre-determined cost of products, labor services, engineering projects, etc. before production and operation activities according to the target, including standard cost. In other words, the combination of cost estimation and target management is called target cost. The management of target cost will help enterprises to strengthen cost management, promote all employees to care about cost and form democratic management, so as to better implement economic responsibility system and further reduce cost ${ }^{[4]}$.

The calculation formula of direct labor standard cost is as follows: direct labor standard cost $=$ standard working hours per unit product $\times$ standard hourly wage rate. After the standard is formulated, the standard labor cost can be determined according to the standard working hours and wage rate, so as to be allocated and included in a certain quantity or batch of products. Of course, there will be differences between the product standard and the actual cost in general, so there is another procedure under the standard cost method to analyze and allocate the variances.

\section{Analysis on the Formation of Labor Cost Variances}

The variance of labor cost occurs in two cases, the variance under single labor and the variance under the influence of multiple factors. The former involves the same level of labor, that is, the processing of a product is completed by the labor at the same level, while the latter involves the labor contributed by workers of multiple levels for the processing of a certain product, and may also be affected by the quality of material grades ${ }^{[5]}$.

\subsection{Formation and analysis of variance under single labor}

In the case of single labor, the labor variance includes two parts, "variance in price" and "variance in quantity". The relevant calculation formulas are as follows: wage rate variance= actual working hours $\times$ (actual wage rate-standard wage rate)

Labor efficiency variance $=($ actual working hours-standard working hours $) \times$ standard wage rate

Direct labor cost variance $=$ wage rate variance + labor efficiency variance

The reasons for wage rate variance include the promotion or demotion of direct production workers, ineffective incentive system, wage rate adjustment, overtime or use of temporary workers, and changes in attendance rate. The reasons for the direct labor efficiency variance include poor working environment, inexperience of workers, poor working mood, too many new workers on duty, improper selection of machines or tools, more equipment failures, improper arrangement of operation plans, too little output to play the advantages of batch saving, etc. Figure 1 shows the formation process of direct labor cost difference.

(1)

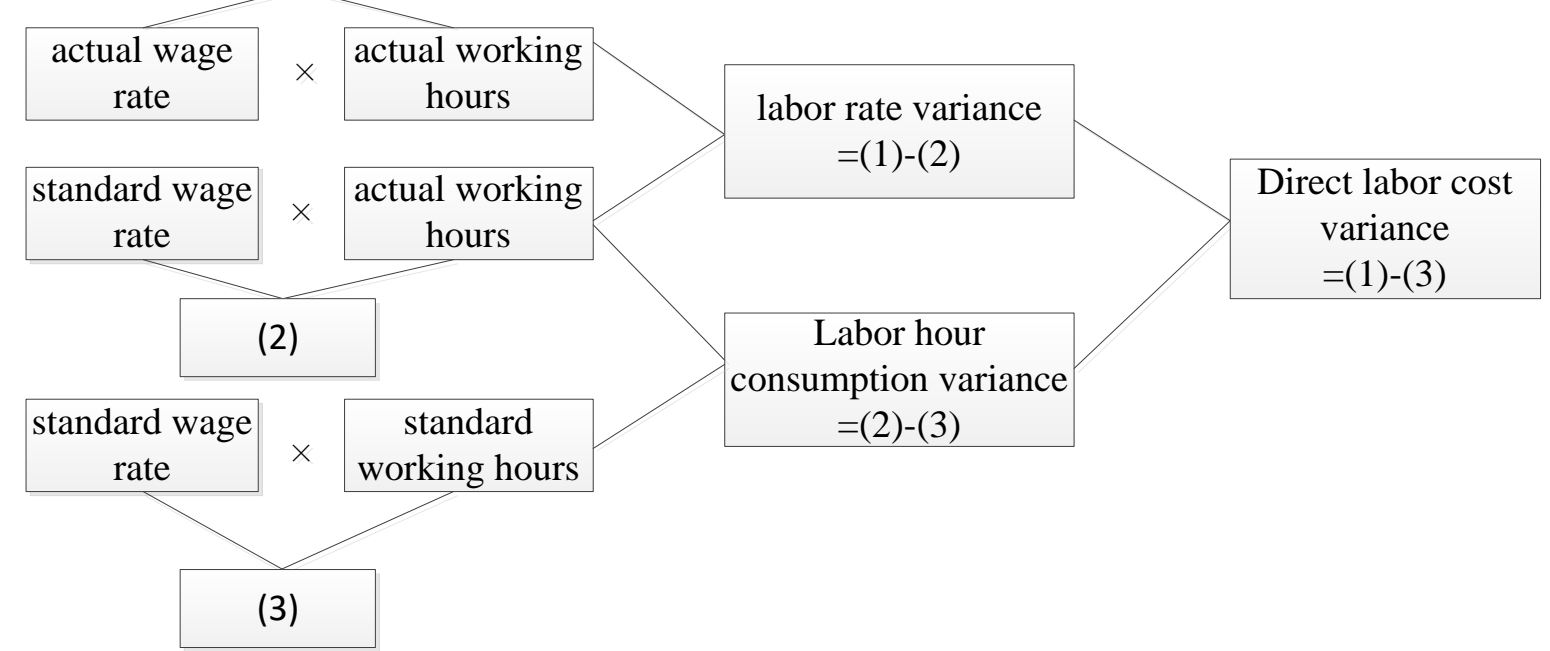

Figure 1 Direct labor cost variance chart 
Example: Zhongsheng Company produces 200 a products in this period, which actually consumes 8,000 hours of labor. The total actual wage is 80,000 yuan, with an average of 10 yuan per working hour. Suppose that the standard wage rate is 9 yuan, and the standard of man hour consumption per unit product is 28 hours. Then, the analysis on the direct labor cost variance is as follows:

The actual labor cost is known as 80,000 yuan, and the standard cost $=200 * 28 * 9=50,400$ yuan. The variance is 29,600 yuan.

The variance in quantity is equal to $(8000-200 * 28) * 9=21,600$ yuan; the variance in price is equal to $(10-9) * 8,000=8,000$ yuan; the total amount is 29,600 yuan.

\subsection{Formation and analysis of variances under the influence of multiple factors}

When there are substitute materials for the raw materials needed in the production of enterprise products, and there are different levels of labor input with different wage rates, the labor cost of products will be affected by many factors such as standard working hours and actual working hours of conventional materials, standard working hours and actual working hours of unqualified materials. Under the influence of many factors, there are still variances in quantity and price in labor cost. However, due to the influence of material and different levels of labor wage rate, the variance in quantity, that is, the variance in efficiency, is embodied in three aspects, namely, the variance caused by conventional materials, unqualified materials and the difference of labor substitution.

Example: Two different levels of labor are needed to produce a product in an enterprise, workers at second level and third level. Given that the actual working time of the workers at third level is 15,200 hours, and that of those at second level is 10,300 hours. In this month, the actual wages and salaries of the third level workers and the second level workers are 216,600 yuan and 163,770 yuan respectively. Two kinds of raw materials with different qualities are put into the production of product A in the company, one of which is of poor quality (unqualified materials), the other is conventional material. In terms of quantity, third-level workers produce 4,800 products made from secondary materials and 7,200 products made from conventional materials, while second-level workers produce 3,200 and 4,800 respectively. Given that the unit standard working hour of such product is $1.2 \mathrm{~h}$ per piece. There is a big difference between actual working hours and standard working hours due to the difference of material quality. The actual working hours of third-level workers are 6,600, and those of second-level workers are 4,400 in the processing with low quality materials, while 8,600 and 5,900 respectively with conventional materials. Given that the level of tertiary workers is lower than that of secondary workers, so the standard wage rate of third-level workers is 14 yuan per hour, and that of second-level workers is 16 yuan per hour.

\section{Analysis on the Wage Variance}

Step 1, sort out the known data according to the above data and form the table 1.

Step 2, calculate the corresponding indicators according to the data in table 1. The calculation process is in table 2 .

According to the known information, the relevant information such as standard working hours, actual working hours and actual distribution rate can be obtained.

Step 3, analyze the variances.

First of all, efficiency variance is calculated. According to the formula: (actual working hoursstandard working hours) $\times$ standard distribution rate $=$ efficiency variance, the efficiency variance can be calculated. The variance between the actual working hours and the standard working hours is: $25,500-24,000=1,500$ hours, the standard wage rate is 14 yuan per hour, so the efficiency variance is equal to 21,000 yuan, but the variance is not real, because part of the production of product $\mathrm{A}$ is completed by second-level workers, the standard wage rate of them should also be considered. 10,300 hours out of 25,500 hours are completed by second-level workers, so the adjusted time is $10,300 \times(16-14)=20,600$. The total efficiency variance is 41,600 yuan. The calculation process is arranged in Table 3: 
Then the efficiency variance is further decomposed, and the variance of low-quality material, conventional material and labor substitution are calculated respectively.

Table 1 Basic information

\begin{tabular}{|c|c|c|c|}
\hline Items & $\begin{array}{c}\text { Third-level workers } \\
\text { (workers with low wage rate) }\end{array}$ & $\begin{array}{c}\text { Second-level workers } \\
\text { (workers with high } \\
\text { wage rate) }\end{array}$ & Subtotal \\
\hline Actual labor cost (yuan) & 216600 & 163770 & 380370 \\
\hline $\begin{array}{c}\text { Actual man hours spent on } \\
\text { low quality materials } \\
\text { (hours) }\end{array}$ & 6600 & 4400 & 1100 \\
\hline $\begin{array}{c}\text { Quantity of products } \\
\text { produced by low quality } \\
\text { materials (PCs.) }\end{array}$ & 4800 & 3200 & 12000 \\
\hline $\begin{array}{c}\text { Standard working hours } \\
\text { (piece / hour) }\end{array}$ & 1.2 & 4800 & 1.2 \\
\hline $\begin{array}{c}\text { Quantity of products } \\
\text { produced by conventional } \\
\text { materials (PCs.) }\end{array}$ & 7200 & 1.2 & 14500 \\
\hline $\begin{array}{c}\text { Standard working hours } \\
\text { (hour /piece) }\end{array}$ & 8600 & 5900 & \\
\hline $\begin{array}{c}\text { Actual working hours of } \\
\text { products produced by } \\
\text { conventional materials } \\
\text { (hours) }\end{array}$ & 1.2 & & \\
\hline
\end{tabular}

The variance of low quality materials is the quantity variance between standard working hours and actual working hours. The variance by low-quality materials = variance of low-quality working hours $\times$ standard wage rate of low-level workers. The use of secondary materials or non-conforming materials in the production of products may lead to the over expenditure of working hours. According to the data calculation in Table 2, the labor consumption standard of low-quality materials is 9,600 hours, and the actual labor consumption is 11,000 hours, so the variance caused by low-quality or unqualified materials is $(11,000-9,600) \times 14=19,600$; the labor variance caused by conventional materials $=$ labor variance of conventional materials $\times$ standard wage rate of low-level workers. In addition, the standard working hours of conventional materials are 14,400 hours, and the actual working hours are 14,500 hours, so the labor wage variance caused by conventional materials is equal to $(14,500-14,400) \times 14=1,400$ yuan. The reason for the variance of labor substitution is that the processing of products is not always done by labor with low wage rate. Due to the number of low-level personnel or in order to improve processing efficiency, enterprises may assign skilled workers, that is, high-level workers. As a result, the wage rate standard changes accordingly. In this case, second-level workers work for 10,300 out of 25,500 actual working hours, so low-level labor substitution by high-level workers will bring about variance in standard wage rate.

The calculation formula of labor substitution variance is: (standard wage rate of high-level workers- standard wage rate of low-level workers) $\times$ actual working hours of high-level workers. According to the information in Table 2, (16-14) $\times 10,300=20,600$, as shown in Table 4 .

Finally, calculate the expense variance, that is, the price variance. According to the price variance formula: (actual wage rate - standard wage rate) $\times$ actual working hours, the spending variance information can be obtained, as shown in Table 5 . In two cases, variance in price of third-level workers $(14.25-14) \times 15,200=3,800$ yuan, variance in price of second-level workers $(15.9-16) \times 10,300=-1,030$ yuan. The total over expenditure is 2,770 yuan. 
Step 4, summarize the variance information.

Table 2 Basic data calculation

\begin{tabular}{|c|c|c|c|c|}
\hline Items & No. & $\begin{array}{c}\text { Third-level workers } \\
\text { (workers with low } \\
\text { wage rate) }\end{array}$ & $\begin{array}{c}\text { Second-level workers } \\
\text { (workers with high } \\
\text { wage rate) }\end{array}$ & Subtota \\
\hline Actual labor cost (yuan) & (1) & 216600 & 163770 & 380370 \\
\hline $\begin{array}{c}\text { Actual man hours spent on } \\
\text { low quality materials } \\
\text { (hours) }\end{array}$ & (2) & 6600 & 4400 & 1100 \\
\hline $\begin{array}{l}\text { Quantity of products } \\
\text { produced by low quality } \\
\text { materials (PCs.) }\end{array}$ & (3) & 4800 & 3200 & 8000 \\
\hline $\begin{array}{c}\text { Standard working hours } \\
\text { per unit product (piece / } \\
\text { hour) }\end{array}$ & (4) & 1.2 & 1.2 & - \\
\hline Standard working hours & (5) $=(3) \times(4)$ & 5760 & 3840 & 9600 \\
\hline $\begin{array}{c}\text { Quantity of products } \\
\text { produced by conventional } \\
\text { materials (PCs.) }\end{array}$ & (6) & 7200 & 4800 & 12000 \\
\hline $\begin{array}{l}\text { Standard working hours } \\
\text { per unit product (hour / } \\
\text { piece) }\end{array}$ & (7) & 1.2 & 1.2 & \\
\hline Standard working hours & 8 & 8640 & 5760 & 14400 \\
\hline $\begin{array}{c}\text { Actual working hours of } \\
\text { products produced by } \\
\text { conventional materials } \\
\text { (hours) }\end{array}$ & (9) $=(7) \times(8)$ & 8600 & 5900 & 14500 \\
\hline Total standard labor hours & $(10=(5)+8$ & 14400 & 9600 & 24000 \\
\hline Total actual labor hours & $(11)=(2)+9$ & 15200 & 10300 & 25500 \\
\hline $\begin{array}{c}\text { Actual wage rate standard } \\
\text { (yuan / hour) }\end{array}$ & $(12)=1 /(11)$ & 14.25 & 15.9 & - \\
\hline
\end{tabular}

Table 3 Summary of efficiency variances

\begin{tabular}{|c|c|c|c|c|}
\hline Items & No. & $\begin{array}{c}\text { Third-level workers } \\
\text { (workers with low } \\
\text { wage rate) }\end{array}$ & $\begin{array}{c}\text { Second-level workers } \\
\text { (workers with high } \\
\text { wage rate) }\end{array}$ & Total \\
\hline Standard working hours & (1) & 14400 & 9600 & 24000 \\
\hline Actual working hours & (2) & 15200 & 10300 & 25500 \\
\hline Time variance & (3) $=(2)-(1)$ & 800 & 700 & 1500 \\
\hline Efficiency variance 1 & (4) $=(3) \times(5)$ & & & 21000 \\
\hline Low standard wage rate & (5) & 14 & & \\
\hline High standard wage rate & (6) & & 16 & \\
\hline Wage rate variance & (7) $=(6)-(5)$ & & 2 & \\
\hline Efficiency variance 2 & (8) $=10300 \times(7)$ & & & 20600 \\
\hline Total efficiency variance & (9) $=(4)+8$ & & & 41600 \\
\hline
\end{tabular}

Table 4 Breakdown of efficiency variance

\begin{tabular}{|c|c|}
\hline Items & Amount of variance \\
\hline Labor variance caused by low quality materials & 19,600 \\
\hline Labor variance caused by conventional materials & 1,400 \\
\hline Labor substitution variance & 20,600 \\
\hline Total efficiency variance & 41,600 \\
\hline
\end{tabular}

Step 5, verify the variance analysis results. The labor variance in the production of product a is 
equal to the difference between the actual labor cost and the standard labor cost.

According to the information in Table 1, the actual labor cost is 380,370, and according to Table 2 , the standard labor cost is $24,000 \times 14$, i.e. 336,000 yuan, so the variance is equal to the difference between 380,370 and 336,000 , i.e. 44,370, which is the adverse variance of over expenditure.

Table 5 Summarize the variance information

\begin{tabular}{|c|c|}
\hline Items & Amount of variance \\
\hline Labor variance caused by low quality materials & 19,600 \\
\hline Labor variance caused by conventional materials & 1,400 \\
\hline Labor substitution variance & 20,600 \\
\hline Total efficiency variance & 41,600 \\
\hline Spending variance of third-level workers & 3,800 \\
\hline Spending variance of second-level workers & $-1,030$ \\
\hline Total spending variance & 3,770 \\
\hline Total labor variance caused by multiple factors & 44,370 \\
\hline
\end{tabular}

Step 6: summarize the variances. Step 7, carry out corresponding accounting treatment. The actual labor cost of the enterprise is recognized according to the workers' wage statement, and is included in the product cost according to the standard cost allocation, and each variance is respectively included in the variance account when it occurs. The accounts related to labor cost include "direct labor", "payroll payable", "direct labor substitution variance", "direct labor variance related to conventional materials", "direct labor variance caused by low-quality materials", "direct labor expense variance " and "production cost". The account of "direct labor" is used for the accounting of actual labor cost, while that of "production cost" for standard labor cost. The variance of overspending is formed in debit, and that of saving is formed in credit. Usually, only standard labor cost is accounted for in products. When finished products appear, they are transferred to the account of "commodity stocks" according to the standard cost, and there are two ways to deal with the variance.

Mode 1: deferral method

Variances are allocated among finished products, unfinished products and products sold in proportion to the standard cost. According to the above case, the corresponding accounting treatment is as follows:

When confirming the actual labor cost, debit: direct labor 380,370, credit: payroll payable 380,370 .

When confirming the standard cost, debit: production cost 336,000, credit: direct labor 336,000.

According to the variance calculation table, debit: labor variance caused by low-quality materials 19,600, labor variance caused by conventional materials 1,400 , labor variance caused by alternative materials 20,166, labor spending variance 2,770, credit: direct labor 44,370. When there are finished products at the end of the period, the variance will be allocated. The process of variance allocation is shown in Table 6 and Table 7

According to the calculation table of equivalent production, the cost of finished products is 280,000 yuan and that of in-process products is 56,000 yuan. At the end of this month, there is a remaining inventory of 50 pieces, that is to say, 450 pieces are sold. The variance distribution is carried out according to the inventory of 50 finished products, sales of 450 , and equivalent on-stream production of about 100.

When products are warehoused, credit: commodity stocks 280,000, debt: production cost 280,000 . The proportion of sales is $450 \div 600=75 \%$, the proportion of commodity stocks is $50 \div$ $600=8.3 \%$, and the proportion of unfinished products is $1-75 \%-8.3 \%=16.7 \%$. The variance data can be obtained by multiplying 4 variances by 3 specific gravity.

During sales, the accounting treatment is as follows: Debit: main business cost 252,000; Credit: commodity stocks 252,000.

The process of variance allocation is as follows:

According to the difference distribution in Table 7, the variances that should be undertaken by 
the three projects are obtained.

According to the variance allocation table, the variance is allocated to three accounts and treated as follows:

Debit: main business cost 33,277.5, commodity stocks 3,682.71, production cost 7,409.79, credit: labor variance of low quality materials 19,600 , labor variance of conventional materials 1,400 , labor substitution variance 20,600, labor expense variance 2,770

Mode 2: direct treatment

The direct treatment is to include all the variances occurred in the current period in the cost of sales, and no longer allocate among the commodity stocks, unfinished products and sales costs.

This is a simplified method. Debit: main business cost 44,370, credit: labor variance of low-quality materials 19,600 , labor variance of conventional materials 1,400 , labor substitution variance 20,600, labor expense variance 2,770

Table 6 Distribution of equivalent output of product A (labor cost part: 700 products put into production, 500 finished, 200 in process, $50 \%$ completed. Assume there are no products in process at the beginning of the period.)

\begin{tabular}{|c|c|c|c|c|}
\hline & Direct material & Direct labor & $\begin{array}{c}\text { Variable } \\
\text { manufacturing } \\
\text { expenses }\end{array}$ & $\begin{array}{c}\text { Fixed } \\
\text { manufacturing } \\
\text { costs }\end{array}$ \\
\hline Cost input (yuan) & (Omitted) & 336000 & (Omitted) & (Omitted) \\
\hline Completed quantity (piece) & (Omitted) & 500 & (Omitted) & (Omitted) \\
\hline $\begin{array}{c}\text { Quantity of unfinished } \\
\text { products }\end{array}$ & (Omitted) & 200 & (Omitted) & (Omitted) \\
\hline $\begin{array}{c}\text { Processing progress } \\
\text { Equivalent quantity of } \\
\text { products in process }\end{array}$ & (Omitted) & $50 \%$ & (Omitted) & (Omitted) \\
\hline Equivalent total quantity & (Omitted) & 100 & (Omitted) & (Omitted) \\
\hline Distribution rate & (Omitted) & 600 & (Omitted) & (Omitted) \\
\hline Cost of finished products & (Omitted) & $\begin{array}{c}56000 \times 500 \\
280000\end{array}$ & (Omitted) & (Omitted) \\
\hline Cost of products in process & (Omitted) & $336000-280000=56000$ & (Omitted) & (Omitted) \\
\hline Total cost & (Omitted) & 336000 & (Omitted) & (Omitted) \\
\hline
\end{tabular}

Table 7 Distribution of variances

\begin{tabular}{|c|c|c|c|c|c|}
\hline Items & $\begin{array}{c}\text { Value of } \\
\text { variance }\end{array}$ & $\begin{array}{c}\text { Variance in } \\
\text { products sold } \\
\text { (proportion 75\%) }\end{array}$ & $\begin{array}{c}\text { Inventory } \\
\text { variance } \\
\text { (proportion: } \\
8.3 \%)\end{array}$ & $\begin{array}{c}\text { Variance in } \\
\text { unfinished products } \\
\text { (proportion 16.7\%) }\end{array}$ & Subtotal \\
\hline $\begin{array}{c}\text { Labor variance of } \\
\text { low quality } \\
\text { materials }\end{array}$ & 19600 & 14700 & 1626.8 & 3273.2 & 19600 \\
\hline $\begin{array}{c}\text { Labor variance of } \\
\text { conventional } \\
\text { materials }\end{array}$ & 1400 & 1050 & 116.2 & 233.8 & 1400 \\
\hline $\begin{array}{c}\text { Variance of } \\
\text { substitution labor }\end{array}$ & 20600 & 15450 & 1709.8 & 3440.2 & 20600 \\
\hline Labor cost variance & 2770 & 2077.5 & 229.91 & 462.59 & 2770 \\
\hline Total & 44370 & 33277.5 & 3682.71 & 7409.79 & 44370 \\
\hline
\end{tabular}

Table 8 Balance sheet after format adjustment (only reflecting inventory items)

\begin{tabular}{|c|c|c|c|c|c|c|}
\hline \multicolumn{2}{|c|}{ Assets } & \multicolumn{3}{|c|}{ Amount } & Liabilities & Amount \\
\hline Inventory & Cost structure & Standard cost & Variance & Actual cost & & \\
\cline { 2 - 7 } & $\begin{array}{c}\text { Finished } \\
\text { goods }\end{array}$ & 28000 & 3682.71 & 31682.71 & & \\
\cline { 2 - 7 } & $\begin{array}{c}\text { Unfinished } \\
\text { products }\end{array}$ & 56000 & 7409.79 & 63409.79 & & \\
\hline \multicolumn{2}{|l|}{ Other items Omitted } & \multicolumn{3}{|l}{} & Total & \\
\hline \multicolumn{2}{|c|}{ Total } \\
\hline
\end{tabular}


Table 9 Income statement after format adjustment

\begin{tabular}{|c|c|c|c|c|}
\hline Items & \multicolumn{3}{|c|}{ Current amount } \\
\hline Operation revenue & \multicolumn{3}{|c|}{370860.75} \\
\hline Operating costs & Expenditure pattern & $\begin{array}{l}\text { Standard cost } \\
\text { transferred in }\end{array}$ & Variance & Subtotal \\
\cline { 2 - 4 } & & 252000 & 33277.5 & 285277.5 \\
\hline Operating margin & & \multicolumn{3}{|c|}{85583.25} \\
\hline
\end{tabular}

Step 8: analyze report items. Different allocation methods lead to different report impacts. Suppose that the cost plus pricing method is adopted in the sales pricing of enterprises, and the rate of addition is $30 \%$.

Method 1: after the balance sheet and profit and loss statement are adjusted, they can reflect the actual cost, standard cost and variance, as shown in Table 8 and Table 9.

According to the mark-on percentage, the income is $285,277.5 \times 1.3=370,860.75$.

The inventory items in the balance sheet under method 2 are all standard costs, and the income statement reflects the data adjusted by standard costs. There is no need to adjust the balance sheet, but the inventory is reflected by the standard cost, and all the variances are transferred to the operating cost without allocating among the three, as shown in Table 10 and Table 11.

Table 10 Balance sheet under direct treatment

\begin{tabular}{|l|l|l|l|l|}
\hline \multicolumn{2}{|l|}{ Asset item } & Ending balance & Liability item & Ending balance \\
\hline \multirow{4}{*}{ Inventory } & Standard cost & & Omitted & \\
\cline { 2 - 6 } & Finished goods & 28000 & Omitted & \\
\cline { 2 - 6 } & $\begin{array}{l}\text { Unfinished } \\
\text { products }\end{array}$ & 56000 & Omitted & \\
\cline { 2 - 6 } & Subtotal & 84000 & Omitted & \\
\hline
\end{tabular}

Table 11 Income statement under the direct treatment method

\begin{tabular}{|c|c|c|}
\hline \multicolumn{2}{|c|}{ Items } & Amount incurred in the current period \\
\hline Operation revenue & (4) $=(3) \times 1.3=38.5281$ \\
\hline Operating cost & Standard cost of products sold & $252000(1)$ \\
\hline & All variances transferred in & $44370(2)$ \\
\hline & Subtotal & $296370(3)$ \\
\hline & Gross margin (5)=(4)-(3) & 88911 \\
\hline
\end{tabular}

It is thus clear that there will be differences in product cost and profit and loss between the two methods.

\section{Conclusion}

When there are many factors, the factors can be further decomposed according to the basic principle of labor variance, and the efficiency variance can be further decomposed into variance from low-quality materials, variance from conventional materials and labor substitution variance. In fact, the variances from low-quality materials and conventional materials can also be further decomposed into the corresponding variances of different levels of workers. The variance in efficiency is the variance in quantity, and the spending variance is the difference between the actual wage and the standard wage rate. Further decomposition of the variance in efficiency can clarify the responsibility of the persons in charge, that is, whether it is attributable to the operation responsibility of the workers. Obviously, the variance from low-quality materials is due to the variance in quantity brought to the workers by the purchase of secondary materials, and the responsibility should be borne by the purchasing department. Of course, even if the purchased materials are conventional, but the standard working hours are set too high or too low, it may also be limited by the workers' own operating skills, resulting in variances in working hours. A balance should be found between the variance in quantity and expenditure. There are two methods to deal with the labor variance, direct method and deferral method, which will affect the balance sheet 
items and the calculation of profit and loss. Therefore, the re-decomposition of labor variance is of great significance in cost management and control of enterprises.

\section{Acknowledgements}

This work was supported by the Construction of Management Accounting System for the Revitalization and Development of the Old Industrial Base in Heilongjiang Province. The project number is $18 \mathrm{GLH735}$

\section{References}

[1] Li Mi. Research on the application of standard cost method and activity-based cost method in cost management of company A: Shenyang University of Technology, 2017.

[2] Lu Huanli. Application of standard cost method in cost management, 2018.

[3] Fu Weibing. Analysis on the integration of standard cost method in enterprise cost management. Accounting learning, 2018.

[4] Niu Yanxiu. New exploration of cost management and accounting -- activity standard cost method: Finance and accounting, 2004.

[5] Deng Simei. Research on the combination of activity-based costing and standard costing, 2018. 